\title{
Population Pharmacokinetic Meta-Analysis to Bridge Ferumoxytol Plasma Pharmacokinetics Across Populations
}

\author{
Nele Plock $\cdot$ Axel Facius $\cdot$ Gezim Lahu $\cdot$ \\ Nolan Wood · Timothy Frigo • Aaron Deveney • \\ Pau Aceves
}

Published online: 5 November 2014

(c) The Author(s) 2014. This article is published with open access at Springerlink.com

\begin{abstract}
Background Ferumoxytol is approved for the treatment of iron-deficiency anaemia (IDA) in adult patients with chronic kidney disease (CKD). Ferumoxytol has recently been investigated for use in all-cause IDA. This analysis was employed to bridge ferumoxytol pharmacokinetics (PK) across populations of healthy subjects and patients with CKD on haemodialysis, and to then make informed inferences regarding the PK behaviour of ferumoxytol in the all-cause IDA population.

Methods The data analysis was performed using NONMEM. Selected parameters were included for covariate testing. Investigations to determine if changes in volume of distribution during haemodialysis improved the model fit were also conducted. The final model was used to simulate PK in healthy volunteers (HVs) and CKD patients with and without haemodialysis.

Results The final model was a two-compartment model with non-linear elimination. During haemodialysis, the central volume $V 1$ was estimated to be reduced by $0.198 \mathrm{~L} /$ h. A positive relationship was identified between initial $V 1$ and observed weight loss during haemodialysis. $V 1$ increased by $0.614 \%$ per kilogram of body weight, and females had an $18.3 \%$ lower $V 1$ than males. Differences
\end{abstract}

\footnotetext{
N. Plock $(\square) \cdot$ A. Facius · G. Lahu

Takeda Pharmaceuticals International $\mathrm{GmbH}$,

Thurgauerstrasse 130, 8152 Glattpark-Opfikon (Zürich),

Switzerland

e-mail: nele.mueller-plock@takeda.com

N. Wood · A. Deveney $\cdot$ P. Aceves

Takeda Development Centre Europe Ltd., London, UK

T. Frigo

AMAG Pharmaceuticals, Inc., Waltham, MA, USA
}

between simulated profiles for different populations were marginal: maximum concentration $\left(C_{\max }\right)$ of 209 vs. $204 \mathrm{ng} / \mathrm{mL}$ and area under the curve from time zero to infinity $\left(\mathrm{AUC}_{\mathrm{inf}}\right)$ of $5,980 \mathrm{vs} .5,920 \mathrm{ng} \cdot \mathrm{h} / \mathrm{mL}$ in $\mathrm{HVs}$ and CKD non-haemodialysis patients, respectively, for a single dose of $510 \mathrm{mg}$.

Conclusions The results indicate that ferumoxytol PK are comparable between HVs and CKD patients. Furthermore, the results are representative of the PK in other populations and can be used to bridge to subjects with general IDA.

\section{Key Points}

Differences in ferumoxytol pharmacokinetics (PK) were observed between healthy subjects and chronic kidney disease (CKD) patients on haemodialysis.

Population PK (popPK) approach identified haemodialysis to be the plausible sole cause of the difference between populations.

As no additional PK difference between healthy volunteers and CKD patients was identified, bridging PK to the all-cause iron-deficiency anaemia population using popPK analysis results was accepted by regulators.

\section{Introduction}

Ferumoxytol is approved for the treatment of iron-deficiency anaemia (IDA) in adult patients with chronic kidney disease (CKD). CKD is characterized by a decreased 
glomerular filtration rate, increased urinary albumin excretion, or both, and is an increasing public health issue. The prevalence of CKD is estimated at $8-16 \%$, worldwide [1]. IDA is common in patients with CKD and results from decreased iron availability, blood loss and increased iron utilization for erythrocyte production in response to erythropoietin-stimulating-agent utilization in this patient group [2, 3]. Correction of iron deficiency (ID) through iron replacement therapy is essential in the optimal management of CKD patients [4].

Recently, ferumoxytol has been investigated for the treatment of IDA in a broader population. Multiple conditions may lead to ID, including poor nutrition status and/ or diseases that restrict iron absorption (such as CKD, inflammatory bowel disease or congestive heart failure) [5]. Irrespective of the cause, ID leads to adverse effects in patients, including anaemia and its well-documented complications. Administration of iron preparations to patients with IDA typically results in significant increases in haemoglobin [6, 7].

Ferumoxytol is a colloidal solution of polyglucose sorbitol-carboxymethylether-coated superparamagnetic iron oxide particles [8] and provides a source of bioactive iron [9-11]. Each $510 \mathrm{mg}$ ferumoxytol dose is injected over approximately $1 \mathrm{~min}$. A second injection is to be administered 2-8 days after the first dose.

Approval of ferumoxytol for the treatment of IDA in adult patients with CKD was based on 11 clinical studies; seven in subjects with CKD (stages 1-5 and 5D) and four in non-CKD subjects. In three studies, two of which were performed in healthy volunteers (HV studies) and one performed in subjects with CKD stage 5D on haemodialysis (CKD study), samples for plasma pharmacokinetics (PK) were obtained.

Data from one study in HVs was previously subjected to a population PK (popPK) analysis. A two-compartment model with zero-order input and Michaelis-Menten elimination best described the PK data from this study [12]. The model also confirmed a previously identified relationship between body weight and volume of distribution.

In the CKD study, during the first $3 \mathrm{~h}$ of the haemodialysis procedure ferumoxytol plasma concentrations either declined minimally or, for the $250 \mathrm{mg}$ dose, increased slightly at time points following the end of intravenous ferumoxytol administration. This observation was explained by changes in plasma volume during haemodialysis, which might decrease volume of distribution for ferumoxytol [13, 14]. However, the hypothesis that concentration increases could be fully explained by these haemodynamic changes had never been explored using a model-based approach.

The analysis objective was therefore to bridge ferumoxytol PK between HVs and CKD patients through a better understanding of the effects of haemodialysis on the PK time course of ferumoxytol via a popPK modelling approach. The analysis was performed with the intention to ultimately gain better insight into the likely ferumoxytol exposures in the general IDA population, for whom PK data are not available.

\section{Methods}

\subsection{Ethics}

Informed consent was obtained from all study participants. The studies were approved by the local Ethics Committees and were carried out in concordance with the International Conference on Harmonisation (ICH) Guidelines for Good Clinical Practice [15].

\subsection{Analysis Population and Data}

An overview of the three clinical studies used in the analysis is presented in Table 1. Studies A and B were conducted in HVs. Study A was an ascending single-dose study with dosing on a per kilogram basis [16], whereas study B, a thorough QT study, used two ferumoxytol doses of $510 \mathrm{mg}$ administered $24 \mathrm{~h}$ apart [12]. Study C investigated two different single doses (125 and $250 \mathrm{mg}$ ) in CKD patients stage 5D during haemodialysis [16]. The HV studies provided PK data from 91 subjects (out of 93 subjects exposed), and the CKD study provided additional PK data from 20 subjects.

\subsection{Analytical Methods}

Plasma from blood samples was collected within $30 \mathrm{~min}$ of collection and was kept frozen $\left(-20^{\circ} \mathrm{C}\right)$ until analysis. Samples were analysed at $39.5{ }^{\circ} \mathrm{C}$ using relaxivity measurements on a $20 \mathrm{MHz}$ NMR. Method validations using spiked plasma samples showed that the data was accurate (97-112\%) over the range of concentrations studied, with a coefficient of variation between 0.5 and $16.5 \%$ (repeatability). The lower limit of quantification (LLOQ) was set at five times the mean relaxivity of normal pooled plasma: 5.83, 6.0 and $11.16 \mu \mathrm{g} / \mathrm{mL}$ for studies A, B and C, respectively.

\subsection{Pharmacokinetic Analysis}

\subsubsection{Development of Structural and Error Model}

PopPK analysis of ferumoxytol plasma concentrations was performed using NONMEM software [17] (version 7, ICON Development Solution LLC, Hanover, MD, USA), with visualization performed in $\mathrm{R}$ (version 2.12.2). 
Table 1 Overview of clinical studies used in popPK analysis

\begin{tabular}{|c|c|c|c|c|c|c|}
\hline $\begin{array}{l}\text { Study no. } \\
\text { (reference) }\end{array}$ & Study design & $\begin{array}{l}\text { Study } \\
\text { population }\end{array}$ & Doses & $\begin{array}{l}\text { No. of } \\
\text { subjects } \\
\text { exposed }\end{array}$ & $\begin{array}{l}\text { IV } \\
\text { administration }\end{array}$ & Sampling time points \\
\hline A [16] & $\begin{array}{l}\text { Phase I, randomized, double- } \\
\text { blind, placebo-controlled, } \\
\text { single-centre, ascending } \\
\text { dose }\end{array}$ & $\begin{array}{l}\text { Healthy } \\
\text { subjects }\end{array}$ & $\begin{array}{l}\text { Part 1: } \\
1 \mathrm{mg} / \mathrm{kg} \\
2 \mathrm{mg} / \mathrm{kg} \\
4 \mathrm{mg} / \mathrm{kg} \\
\text { Part } 2: \\
4 \mathrm{mg} / \mathrm{kg}\end{array}$ & $\begin{array}{l}8 \\
8 \\
8\end{array}$ & $\begin{array}{l}\text { Part 1: } \\
60 \mathrm{mg} / \mathrm{min} \\
\text { Part 2: } \\
30 \mathrm{mg} / 20 \mathrm{~s} \\
30 \mathrm{mg} / 10 \mathrm{~s} \\
30 \mathrm{mg} / \mathrm{s}\end{array}$ & $\begin{array}{l}\text { Pre-dose, } 5,10,15 \text {, and } 30 \mathrm{~min} \text {, and } 1,4,8 \text {, } \\
24,48,72 \text {, and } 168 \mathrm{~h}(n=12)\end{array}$ \\
\hline B [12] & $\begin{array}{l}\text { Phase I, randomized, double- } \\
\text { blind, active- and placebo- } \\
\text { controlled, parallel group, } \\
\text { single-centre }\end{array}$ & $\begin{array}{l}\text { Healthy } \\
\text { subjects }\end{array}$ & $2 \times 510 \mathrm{mg}$ & 58 & $\begin{array}{l}17 \mathrm{~mL} \text { over } \\
17 \mathrm{~s}\end{array}$ & $\begin{array}{l}\text { Pre-dose, } 5,10,15 \text { and } 30 \min , 1,4,8,12, \\
24,24.08,24.167,24.25,24.5,25,28,32, \\
36,48,72,96,120 \text {, and } 144 \mathrm{~h} \text { after first } \\
\text { dose }(n=23)\end{array}$ \\
\hline C [16] & $\begin{array}{l}\text { Phase I, open-label, non- } \\
\text { randomized, parallel } \\
\text { group, ascending dose, } \\
\text { single-centre }\end{array}$ & $\begin{array}{l}\text { CKD } \\
\text { stage 5D } \\
\text { on HD }\end{array}$ & $\begin{array}{l}1 \times 125 \mathrm{mg} \\
1 \times 250 \mathrm{mg}\end{array}$ & $\begin{array}{l}10 \\
10\end{array}$ & $\begin{array}{l}\text { Over } 5 \text { min } \\
\text { within } \\
30 \text { min after } \\
\text { dialysis start }\end{array}$ & $\begin{array}{l}\text { Pre-dose, } 5,10,15 \text {, and } 30 \mathrm{~min} \text {, and } 1,2,3 \text {, } \\
\quad 48 \text {, and } 96 \mathrm{~h}(n=10)\end{array}$ \\
\hline
\end{tabular}

popPK population pharmacokinetics, $I V$ intravenous, $C K D$ chronic kidney disease, $H D$ haemodialysis

Samples with ferumoxytol concentration less than LLOQ were treated as missing. The first-order conditional estimation method with interaction was used throughout model development. Model development was initiated using a model previously developed for ferumoxytol study B [12]. This model was extended by exploring additional betweensubject variability (BSV), assuming lognormal distribution of individual parameter estimates and additive/proportional residual error structures, in addition to exploring structural elements of the model. Models were evaluated using standard goodness-of-fit plots (observed concentrations versus population and individual-predicted concentrations and plots assessing the conditional and individual weighted residuals), decrease in objective function value (OFV), parameter variance, individual plots and biological plausibility of parameter estimates. In order to evaluate whether the model could reproduce the observed data with respect to central tendency and observed variability, visual predictive checks (VPCs) [18] were performed during model development.

\subsubsection{Covariate Model Development}

The effect of the following covariates on ferumoxytol PK was investigated:

- Demographics: age, body weight (WGT), body mass index (BMI), sex (SEX), ethnicity

- Study population (i.e. healthy subjects vs. CKD patients)

- Measures of iron: baseline serum iron, ferritin, transferrin saturation (TSAT), total iron binding capacity (TIBC), unsaturated iron binding capacity (UIBC), haemoglobin
- Haemodialysis (yes/no)

- Body weight loss due to haemodialysis (WLO, obtained from pre- and post-dialysis weight assessment, zero for all non-haemodialysis subjects)

As a general rule, the confounding effects of highly correlated covariates were considered in covariate identification and the interpretation of covariate effects. A covariate was tested if justified from plots showing individual empirical Bayes estimates of the parameters of interest against possible covariates. In addition, physiologically plausible relations (e.g. measures of iron against parameters related to ferumoxytol clearance from the circulation, body weight on volume, haemodialysis on clearance or volume) were tested irrespective of the visual plot assessment. Models were compared using a likelihood ratio test, using the minimum OFV as an approximation to -2 times the log-likelihood. The covariate analysis followed the forward inclusion $(p \leq 0.05) /$ backward elimination $(p \leq 0.001)$ procedure.

Continuous covariates were implemented into the model using a linear relation, centered around a typical covariate value, and expressed as percentage change:

$\theta_{\text {ind }}=\theta_{\text {pop }}\left(1+\frac{\left(\operatorname{Cov}-\operatorname{Cov}_{\text {norm }}\right) \theta_{\text {Cov }}}{100}\right)$

where $\theta_{\text {ind }}$ is the individual model-predicted PK parameter (e.g. clearance) for an individual with covariate value Cov, $\theta_{\text {pop }}$ represents the population central tendency for the respective PK parameter, $\operatorname{Cov}_{\text {norm }}$ represents the normalization value (e.g. population median) of the covariate, and $\theta_{\text {Cov }}$ represents the covariate effect in percentage.

Categorical covariates were incorporated using a fractional change model, estimating percentage difference to 
the reference category. For covariates with two categories (encoded as 1 and 2), this would be described by the following equation:

$\theta_{\text {ind }}=\theta_{\text {pop }}\left(1+\frac{(\operatorname{Cov}-1) \theta_{\operatorname{Cov}}}{100}\right)$

where $\theta_{\text {ind }}$ is the individual model-predicted PK parameter (e.g. clearance) for an individual with covariate value Cov, $\theta_{\text {pop }}$ represents the popPK parameter of the reference category, and $\theta_{\mathrm{Cov}}$ represents the covariate effect in percentage.

\subsection{Model Evaluation}

The final model was evaluated by VPC [18] and nonparametric bootstrapping methods.

For the VPC, new individual plasma concentration-time profiles were simulated based on 200 simulations from the original dataset and the parameter estimates from the final model, respectively. All measured concentrations were visually compared with the corresponding median and $90 \%$ prediction interval. The plots were stratified by treatment, defined as dose in $\mathrm{mg}$.

The non-parametric bootstrap re-sampling technique was applied to assess the robustness of the model. Similar to VPC, sampling was performed stratified on treatment to assure a similar population in each data set. The final model was fit to 1,000 bootstrap data sets. Results were evaluated by means of summary statistics and comparison with the final model-predicted parameter estimates, using final parameter estimates for all runs.

\subsection{Simulations and Statistical Analysis}

The final model was used to simulate plasma concentration-time profiles with the intention of comparing ferumoxytol exposures in HVs with those of patients with CKD. For CKD patients on haemodialysis, PK profiles were simulated such that drug administration took place after completion of $1 \mathrm{~h}$ of haemodialysis, as per the product label [19]. For comparison, simulations were also performed following a single dose in healthy subjects and in CKD patients without haemodialysis.

To create the simulation data set, three subsets were initially created which used the same number of subjects and same covariate information as in the data sets for studies B and C. For CKD patients not on haemodialysis, WLO was set to zero. The data set merged from all subsets was simulated 100 times, using the final covariate model.

To illustrate the approved dosing regimens, an additional simulation was performed for the combined data set of HVs and CKD patients not on haemodialysis, at a dose of $510 \mathrm{mg}$. For each simulation scenario, ferumoxytol was
Table 2 Categorical count data for subjects included in the analysis

\begin{tabular}{lrrr}
\hline & \multicolumn{2}{l}{ Study } & \\
\cline { 2 - 4 } & A & B & C \\
\hline Sex & & & \\
Female & 16 & 24 & 10 \\
Male & 17 & 34 & 10 \\
Ethnicity & & & \\
Asian/other & 0 & 1 & 1 \\
Black/African American & 20 & 46 & 15 \\
Hispanic, Hispanic/Latino & 7 & 3 & 0 \\
Caucasian/White & 6 & 8 & 4 \\
Total & 33 & 58 & 20 \\
\hline
\end{tabular}

administered twice: once on day one, followed by a second administration 2, 5 or 8 days later.

All simulated profiles were subjected to a non-compartmental analysis (NCA) using Pheonix WinNonlin 6.3 (Pharsight Corporation, St Louis, MO, USA), and the PK parameters generated were summarized using descriptive statistics.

\section{Results}

\subsection{Data}

The popPK analysis was based on plasma PK data from three studies. Apart from the pre-dose values, 1,686 observation records were available, 29 of which were below the LLOQ. With the exception of two time points, the LLOQ values all originated from the 48- and 96-h samples in study $\mathrm{C}$, i.e. the data set provided limited information for late time points in the CKD population. Complete covariate information was available for all 111 subjects; no data had to be imputed or excluded from the analysis.

The categorical covariate distribution is presented in Table 2. There was a balanced distribution of sexes within the studies (45 vs. $55 \%$ females and males, respectively). Most of the data was obtained from subjects with Black or African American ethnicity (73\%), followed by Caucasians $(16 \%)$. Only a small number of subjects were of Hispanic $(9 \%)$ or Asian/other (2\%) ethnic origin. The continuous covariates are shown in Table 3. Overall, subjects had similar covariate distributions between studies A and $\mathrm{B}$, whereas in study $\mathrm{C}$ subjects were older, had higher ferritin and TSAT values and lower TIBC and UIBC values. This difference was expected due to the subjects' disease status.

Observed dose-normalized concentrations up to $20 \mathrm{~h}$ after the first dose are presented in Fig. 1. The range of 
Table 3 Continuous covariate distributions for subjects included in the analysis

\begin{tabular}{|c|c|c|c|c|c|c|c|c|c|c|c|}
\hline Study & & $\begin{array}{l}\text { Age } \\
\text { (years) }\end{array}$ & $\begin{array}{l}\text { BMI } \\
\left(\mathrm{kg} / \mathrm{m}^{2}\right)\end{array}$ & $\begin{array}{l}\text { Weight } \\
(\mathrm{kg})\end{array}$ & $\begin{array}{l}\text { Haemoglobin } \\
(\mathrm{g} / \mathrm{dL})\end{array}$ & $\begin{array}{l}\text { TSAT } \\
(\%)\end{array}$ & $\begin{array}{l}\text { TIBC } \\
(\mu \mathrm{g} / \mathrm{dL})\end{array}$ & $\begin{array}{l}\text { Ferritin } \\
(\mathrm{ng} / \mathrm{mL})\end{array}$ & $\begin{array}{l}\text { Serum } \\
\text { iron }(\mu \mathrm{g} / \\
\mathrm{dL})\end{array}$ & $\begin{array}{l}\text { UIBC } \\
(\mu \mathrm{g} / \mathrm{dL})\end{array}$ & $\begin{array}{l}\text { Haemodialysis }{ }^{\text {a }} \\
\text { weight loss }(\mathrm{kg})\end{array}$ \\
\hline \multirow[t]{5}{*}{$\mathrm{A}(n=33)$} & Mean & 33.0 & 27.3 & 79.8 & 12.9 & 21.0 & 332 & 39.8 & 67.8 & 265 & $\mathbf{0}$ \\
\hline & SD & 7.53 & 5.56 & 15.9 & 1.24 & 7.60 & 45.3 & 31.8 & 20.9 & 54.7 & 0 \\
\hline & Median & 31 & 27.0 & 79 & 12.8 & 21 & 327 & 24.5 & 65 & 262 & 0 \\
\hline & Min & 20 & 17.7 & 46.5 & 11.1 & 7.4 & 249 & 4.4 & 30 & 149 & 0 \\
\hline & Max & 58 & 40.8 & 115 & 15.6 & 40.2 & 429 & 109 & 107 & 380 & 0 \\
\hline \multirow[t]{5}{*}{$\mathrm{B}(n=58)$} & Mean & 30.4 & 25.8 & 76.7 & 13.3 & 15.7 & 406 & 26.2 & 63.4 & 343 & $\mathbf{0}$ \\
\hline & SD & 8.0 & 2.7 & 12.7 & 1.2 & 6.6 & 43.9 & 19.5 & 26.3 & 50.3 & 0 \\
\hline & Median & 30 & 26.2 & 79 & 13.5 & 15.5 & 402 & 20.5 & 61.5 & 339 & 0 \\
\hline & Min & 18 & 19.9 & 49.4 & 10.7 & 3 & 317 & 7 & 16 & 232 & 0 \\
\hline & Max & 45 & 30.0 & 102 & 15.9 & 31 & 503 & 88 & 127 & 452 & 0 \\
\hline \multirow[t]{5}{*}{$\mathrm{C}(n=20)$} & Mean & 60.7 & 29.6 & 84.2 & 12.4 & 29.6 & 203 & 259 & 58.8 & 144 & 2.8 \\
\hline & SD & 11.8 & 4.29 & 14.5 & 1.01 & 9.68 & 40.1 & 154 & 19.8 & 41.0 & 1.01 \\
\hline & Median & 64 & 29.1 & 83.9 & 12.4 & 26.5 & 206 & 215 & 55.5 & 140 & 2.65 \\
\hline & Min & 34 & 21.5 & 55 & 10.7 & 14 & 128 & 86 & 32 & 91.5 & 1.1 \\
\hline & Max & 77 & 37.9 & 107 & 14.6 & 47 & 275 & 677 & 99 & 222 & 4.8 \\
\hline
\end{tabular}

$B M I$ body mass index, TSAT transferrin saturation, TIBC total iron binding capacity, UIBC unsaturated iron binding capacity, calculated as the absolute difference between the TIBC and serum iron, $S D$ standard deviation, min minimum, max maximum, $C K D$ chronic kidney disease

${ }^{a}$ Haemodialysis weight loss only for CKD patients on haemodialysis, otherwise values were fixed to zero

observed concentrations is very similar between HVs and CKD patients with haemodialysis. However, in contrast to $\mathrm{HVs}$, the plots illustrate a concentration increase in the CKD population over the first $3 \mathrm{~h}$ following ferumoxytol administration. This contrasts common PK knowledge about drug distribution and elimination processes, from which one would expect plasma concentrations to decrease after intravenous drug administration has ended. As the first $3 \mathrm{~h}$ correspond to the duration of haemodialysis, the data indicate that haemodialysis might potentially serve to explain the observed difference.

\subsection{Population Pharmacokinetic Model Development}

Initial explorations using data from HV studies A and B suggested that, in general, the previously published model structure resulting from an analysis of study B [12] adequately described the extended data set. The inclusion of a Hill factor on the Michaelis-Menten elimination term improved the model fit (decrease in OFV by 8.2 points), as well as the use of a combined additive + proportional residual error term. As previously described [12], a linear relation between body weight and central volume $(V 1)$ was included, whereas BSV on the Michaelis-Menten constant $\mathrm{Km}$ was not supported. After adding data from the CKD study, a slope (VSLOPE) parameter was included for haemodialysis subjects to describe volume change over time, so as to account for the effects of haemodialysis on central volume of distribution. Volume was fixed to return to pre-dialysis values within $3 \mathrm{~h}$ after dialysis end [20], using the parameter VSLOPEUP, as no PK observations were available during this time period. This model was able to describe the increasing plasma concentrations observed in study $\mathrm{C}$ after dosing. Removal of redundant BSV improved model stability without significant increases in OFV. Fixing the Hill factor to its final estimate led to a stable model with precise parameter estimates and a good fit to the data. This model was used for further covariate model development. Some shrinkage was present in the BSV of the peripheral volume $V 2$, indicating that visual inspection of individual Bayes estimates against covariate values might not be informative [21]. Covariates were therefore tested on $V 2$ based on physiological plausibility, only. As a final step after covariate model development, the Michaelis-Menten elimination term was reparameterized to express $\mathrm{Km}$ as a concentration as, from a mechanistic perspective, this parameterization was more reasonable in a model with changing central volume. The Hill factor was removed to stabilize the final model.

\subsection{Final Model}

The final model was a two-compartment PK model with Michaelis-Menten elimination, and used the following equations: 
(a)

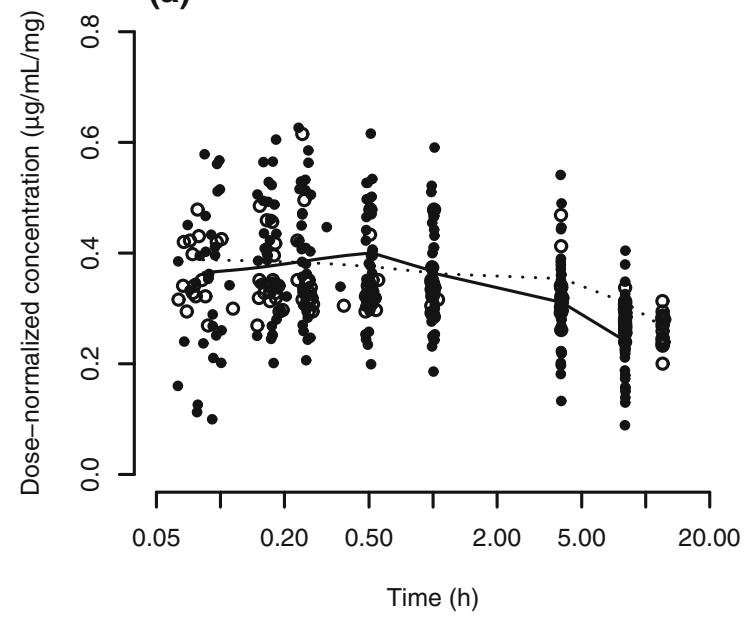

Fig. 1 Dose-normalized plasma concentration-time curves of ferumoxytol for (a) healthy volunteers and (b) CKD patients on haemodialysis. For better visualization, only early time points are shown, and data on the abscissae is presented on the log-scale. Time points were jittered using the jitter function in $R$ to improve visibility of single observations. In the healthy volunteer subplot, closed and empty

$$
\begin{aligned}
\frac{\mathrm{d} A 1}{\mathrm{~d} t}= & -\frac{Q}{A 3} \cdot A 1+\frac{Q}{V 2} \cdot A 2-V_{\max } \cdot \frac{C 1}{\mathrm{Km}+C 1} \\
& \text { with } C 1=\frac{A 1}{A 3} \\
\frac{\mathrm{d} A 2}{\mathrm{~d} t}= & \frac{Q}{A 3} \cdot A 1-\frac{Q}{V 2} \cdot A 2
\end{aligned}
$$

A3 was initialized to correspond to $V 1$ and coded as

$$
\frac{\mathrm{d} A 3}{\mathrm{~d} t}=\text { slope }
$$

to describe the volume changes. We set slope $=0$ for subjects without haemodialysis or after volume recovery following haemodialysis; slope $=$ VSLOPE in subjects during haemodialysis and slope $=-$ VSLOPEUP in subjects $3 \mathrm{~h}$ after haemodialysis, respectively.

The final model parameters are presented in Table 4. $V 1$ and $V 2$ were estimated to be small $(2.8$ and $0.35 \mathrm{~L}$, respectively). During haemodialysis, $V 1$ was estimated to be reduced by $0.198 \mathrm{~L} / \mathrm{h}$ over a period of $3 \mathrm{~h}$ (total volume loss of $0.59 \mathrm{~L}$ ). It was also identified that patients with the highest observed weight loss during haemodialysis were those with the largest initial $V 1$. Overall, $V 1$ differed by $0.614 \%$ per kilogram difference in body weight, and females had an $18.3 \%$ lower $V 1$ than males.

\subsection{Model Evaluation}

VPCs to assess the predictive ability of the model are presented in Fig. 2. Overall, the model captured the central tendency as well as the variability in the observed PK data. (b)

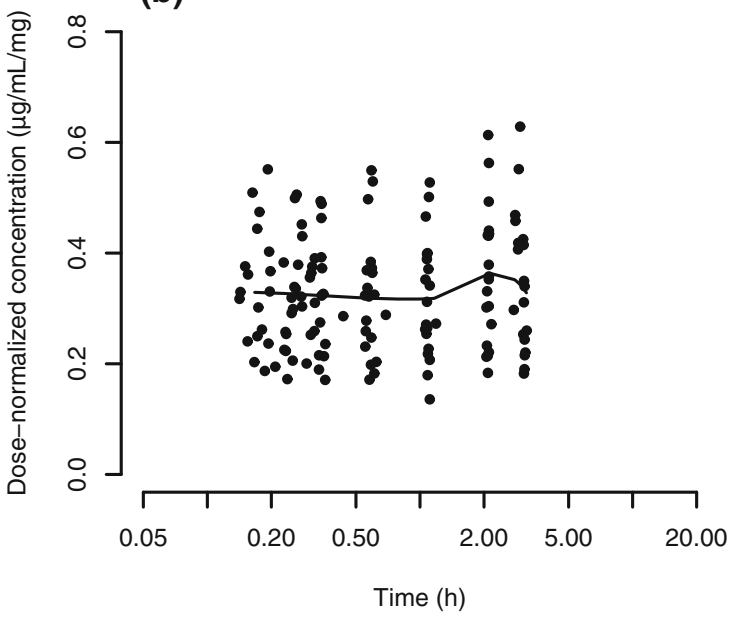

circles correspond to concentration values obtained from studies A and $\mathrm{B}$, respectively, while all concentration values in the CKD subplot originate from study C. Smooth lines were generated using the loess function in $R$, with the solid and dashed lines in the healthy volunteer subplot corresponding to data from studies A and B, respectively. $C K D$ chronic kidney disease

Concentrations were slightly overpredicted in the $1 \mathrm{mg} / \mathrm{kg}$ dose group. Plots showing the first $3 \mathrm{~h}$ after the first dose illustrate the slope difference between healthy subjects and CKD patients receiving haemodialysis.

Of all the bootstrap runs performed, 146 minimized successfully; all others terminated with rounding errors. All runs were used to evaluate the robustness of the final model [22]. The results of the bootstrap analysis and the comparison with the final model parameters are presented in Table 4. The parameter estimates from the final model fell within the $95 \%$ confidence interval of the bootstrap parameter estimates, with the highest bias from the bootstrap median being $2.3 \%$ for BSV on central volume. Overall, the bootstrap analysis supports the robustness and stability of the final model.

\subsection{Simulations and Statistical Analysis}

Single-dose plasma concentration-time profiles for CKD patients and HVs are shown in Fig. 3 and Table 5. In CKD patients with and without haemodialysis, initial concentrations at time zero differ by $\sim 11 \%$. This result is an effect of the covariate influence WLO on central volume of distribution.

As a result of the changes in $V 1$ during dialysis, concentrations increase in the haemodialysis population. Overall, maximum concentrations between CKD patients with or without haemodialysis differ only slightly $(\sim 8 \%)$. In addition, due to the saturable Michaelis-Menten elimination behaviour of ferumoxytol, differences in $V 1$ also result in relatively small differences in AUC. 
Table 4 Parameter estimates and bootstrap results of the final ferumoxytol PK model

\begin{tabular}{|c|c|c|c|c|}
\hline & \multirow[t]{2}{*}{ Final model estimate $[\% \mathrm{RSE}]^{\mathrm{a}}$} & \multicolumn{3}{|c|}{ Bootstrap results } \\
\hline & & BS estimate & $95 \%$ BS CI & $\%$ Bias $^{\mathrm{b}}$ \\
\hline$V_{\max }(\mathrm{mg} / \mathrm{h})$ & $16.5[4.8]$ & 16.4 & $14.5-18.5$ & 0.7 \\
\hline $\mathrm{Km}(\mathrm{mg} / \mathrm{L})$ & $96.7[7.2]$ & 95.5 & $76.3-117$ & 1.3 \\
\hline$V 1(\mathrm{~L})$ & $2.78[3.3]$ & 2.78 & $2.64-2.94$ & -0.04 \\
\hline$Q(\mathrm{~L} / \mathrm{h})$ & $0.0289[8.6]$ & 0.0291 & $0.0230-0.0376$ & -0.7 \\
\hline$V 2(\mathrm{~L})$ & $0.348[11.5]$ & 0.353 & $0.258-0.482$ & -1.4 \\
\hline VSLOPE (L/h) & $-0.198[7.8]$ & -0.197 & -0.248 to -0.146 & 0.2 \\
\hline WGT on $V 1(\% / \mathrm{kg})$ & 0.614 [24.9] & 0.611 & $0.331-0.896$ & 0.5 \\
\hline$V 1$ change for females $(\%)$ & $-18.3[16.7]$ & -18.5 & -23.7 to -12.3 & -0.8 \\
\hline WLO on $V 1(\% / \mathrm{kg}$ weight loss $)$ & $7.22[23.4]$ & 7.33 & $3.03-11.4$ & -1.5 \\
\hline Additive error $(\mu \mathrm{g} / \mathrm{mL})$ & $1.40[20.1]$ & 1.40 & $0.03-1.99$ & 1.7 \\
\hline Proportional error (\%CV) & $7.85[1.4]$ & 7.80 & $6.83-8.84$ & 0.7 \\
\hline $\mathrm{BSV}_{V_{\max }}(\% \mathrm{CV})$ & 17.5 [18.2] & 17.2 & $14.0-22.3$ & 1.9 \\
\hline $\mathrm{BSV}_{V 1}(\% \mathrm{CV})$ & $16.8[16.5]$ & 16.4 & $14.3-18.4$ & 2.3 \\
\hline $\mathrm{BSV}_{V 2}(\% \mathrm{CV})$ & $52.7[33.2]$ & 52.7 & $31.4-79.1$ & -0.1 \\
\hline
\end{tabular}

$P K$ pharmacokinetics, $R S E$ relative standard error as a percentage, $B S$ bootstrap, $C I$ confidence interval, $B S V$ between-subject variability, $C V$ coefficient of variation (calculated as $\operatorname{sqrt}\left(\omega^{2}\right) \times 100$ )

${ }^{a}$ RSE for BSV and residual error given on the variance scale

${ }^{\mathrm{b}}$ Calculated as (final model estimate - BS estimate)/BS estimate

To investigate differences in exposure between CKD patients and HVs, the simulated profile in HVs was compared with that of non-haemodialysis CKD patients. As shown in Fig. 3, differences between the two populations were marginal. This is also reflected in the median NCA parameter values, which were comparable between the two populations (Table 5).

The simulation results for repeated dosing are presented in Fig. 4 and Table 6. They confirm that exposure following dosing 5 and 8 days apart is comparable to day 1 exposure. Following the shorter dosing interval of 2 days apart, the peak and total exposure of ferumoxytol is slightly higher, with median maximum concentration $\left(C_{\max }\right)$ and median total area under the curve from time zero to infinity (AUC ${ }_{\text {inf }}$ ) of two doses being $\sim 21$ and $\sim 11 \%$ higher compared with redosing after 5-8 days.

\section{Discussion}

The described popPK model was developed in an effort to bridge ferumoxytol plasma PK across populations through a model-based approach. The present model is an expansion of a previously available two-compartment model with saturable elimination [12], using additional data from healthy subjects (study A) and CKD patients on haemodialysis (study C). Some minor modifications were introduced into the model, e.g. a Hill factor was temporarily included on the Michaelis-Menten elimination term and models for BSV and residual error were reassessed. In addition, the influence of body weight on central volume was included during base model development as this covariate had previously been related to central volume. The final model was a two-compartment model with a concentration-dependent maximum effect $\left(E_{\max }\right)$ term used to describe capacity-limited ferumoxytol elimination from plasma. The model resulted in adequate characterization of the ferumoxytol data under most conditions. Small doses of $1 \mathrm{mg} / \mathrm{kg}$ (approximately $70 \mathrm{mg}$ ) were overpredicted by the model, which was considered acceptable given that the approved dose of $510 \mathrm{mg}$ is about sevenfold higher.

The final parameter estimates suggest that ferumoxytol is mainly constrained to plasma volume, with a total estimated volume of $3.13 \mathrm{~L}$ [23]. This was expected given the large molecular weight of ferumoxytol $(750 \mathrm{kDa})$, and is in line with previous results [12] which reported a similar volume of distribution of $3.15 \mathrm{~L}$. As in the previous analysis, a saturable elimination process was found to adequately describe ferumoxytol plasma concentrations, and absolute values in $V_{\max }$ and $\mathrm{Km}$ differed only slightly from previous results.

Different covariate relations were incorporated into the current model in an attempt to explain the BSV in model parameters. While none of the baseline laboratory values related to iron metabolism displayed a significant relationship to any of the model parameters across the ranges studied, the demographic parameters sex and body weight were related to central volume of distribution. The 
(a)

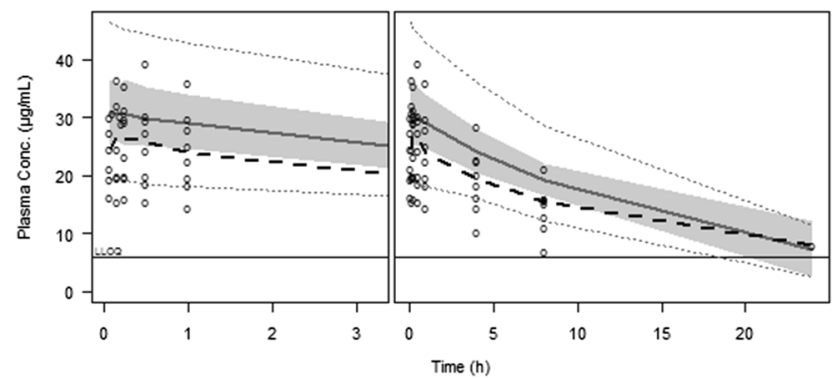

(b)

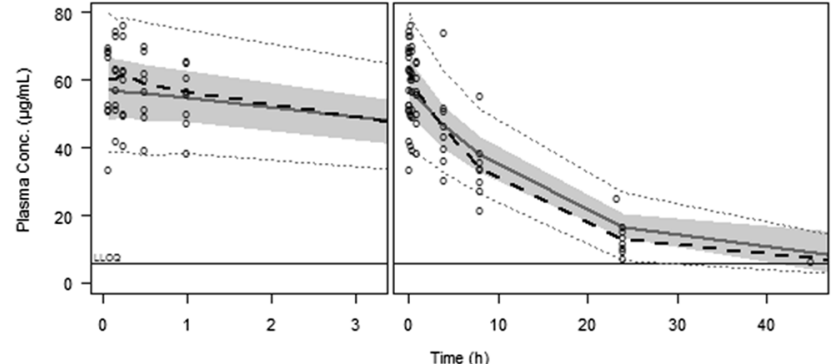

(c)

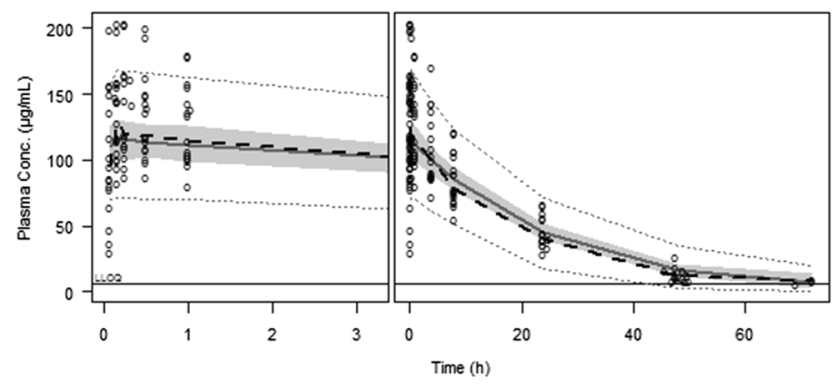

Fig. 2 Visual predictive checks for the final ferumoxytol model for all treatment regimens. Each subplot shows the first $3 \mathrm{~h}$ after the first dose in the left-hand panel, and the whole range of observations of the respective dose in the right-hand panel. Subplots a-c correspond to (d)

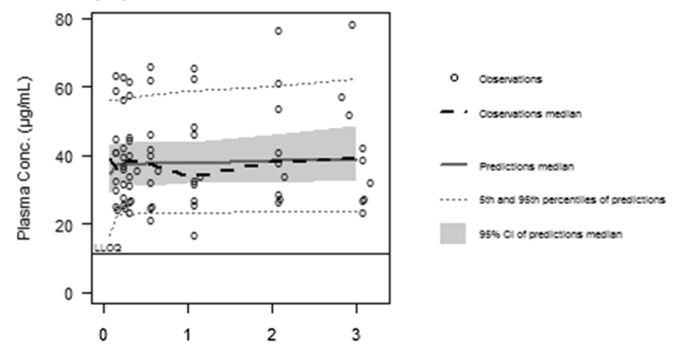

(e)

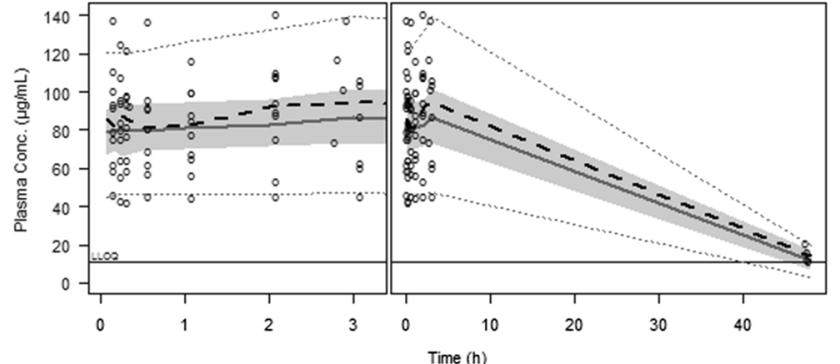

(f)

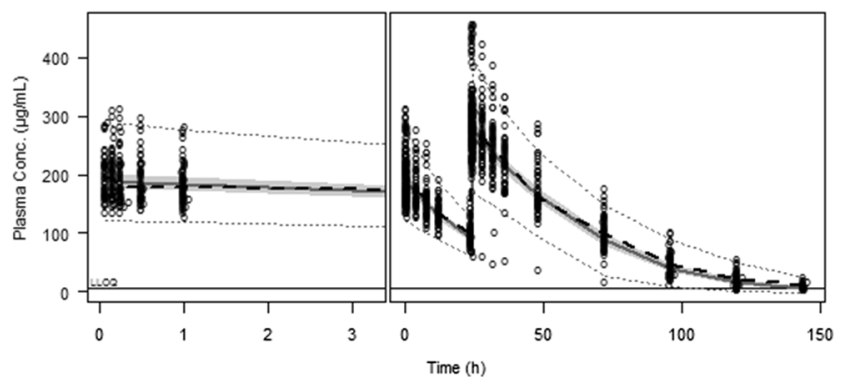

observations from study A at doses of 1,2 and $4 \mathrm{mg} / \mathrm{kg}$, respectively. Subplots d-e correspond to observations from study C at doses of 125 and $250 \mathrm{mg}$, respectively. Subplot $\mathbf{f}$ represents observations from study B following two 510-mg doses administered within $24 \mathrm{~h}$
Table 5 NCA results for simulated profiles in healthy volunteers and CKD patients after administration of $510 \mathrm{mg}$ ferumoxytol

NCA non-compartmental analysis, $C K D$ chronic kidney disease, $C_{\max }$ maximum concentration, $A U C_{\text {inf }}$ area under the curve from time zero to infinity, $A U C_{0-48}$ area under the curve from time zero to $48 \mathrm{~h}, t_{1 / 2}$ elimination half-life

\begin{tabular}{llllll}
\hline Group & Percentile & $C_{\max }(\mu \mathrm{g} / \mathrm{mL})$ & $\mathrm{AUC}_{\mathrm{inf}}(\mu \mathrm{g} \cdot \mathrm{h} / \mathrm{mL})$ & $\mathrm{AUC}_{0-48 \mathrm{~h}}(\mu \mathrm{g} \cdot \mathrm{h} / \mathrm{mL})$ & $t_{1 / 2}(\mathrm{~h})$ \\
\hline CKD haemodialysis & Median & $\mathbf{1 8 8}$ & $\mathbf{5 , 5 4 0}$ & $\mathbf{4 , 2 0 0}$ & $\mathbf{2 2 . 8}$ \\
& 5 th & 126 & 3,920 & 3,060 & 13.5 \\
& 95 th & 309 & 8,080 & 5,930 & 38.5 \\
CKD non-haemodialysis & Median & $\mathbf{2 0 4}$ & $\mathbf{5 , 9 2 0}$ & $\mathbf{4 , 7 0 0}$ & $\mathbf{2 0 . 1}$ \\
& 5 th & 140 & 4,190 & 3,460 & 12.4 \\
Healthy volunteers & 95 th & 303 & 8,640 & 6,440 & 34.0 \\
& Median & $\mathbf{2 0 9}$ & $\mathbf{5 , 9 8 0}$ & $\mathbf{4 , 7 7 0}$ & $\mathbf{1 9 . 9}$ \\
& 5 th & 145 & 4,280 & 3,560 & 12.0 \\
& 95 th & 306 & 8,640 & 6,550 & 32.9 \\
\hline
\end{tabular}

relationship between body weight and volume of distribution had been reported previously, with a relative increase in $V 1$ of $0.84 \%$ per kilogram body weight [12]. The slightly smaller relative increase in $V 1$ of $0.61 \%$ per kilogram body weight identified in this analysis might be explained by the additional influence of sex on volume, as males, in addition to their general difference in body composition, tend to be heavier than females. Sex was not investigated as a potential covariate in the previously published model [12], thus the results of the current analyses are considered to be plausible. The European Summary of Product Characteristics for ferumoxytol [24] 
Fig. 3 Simulation of $510 \mathrm{mg}$ ferumoxytol dose in healthy subjects and CKD patients with or without haemodialysis. Plot a shows simulated plasma profiles for CKD patients with (hatched area) and without (gray shaded area) haemodialysis. Plot $\mathbf{b}$ shows simulated profiles for CKD patients not on haemodialysis (hatched area) against healthy volunteers (gray shaded area). Bold solid lines and areas represent median and $90 \%$ prediction interval, respectively. $C K D$ chronic kidney disease (a)

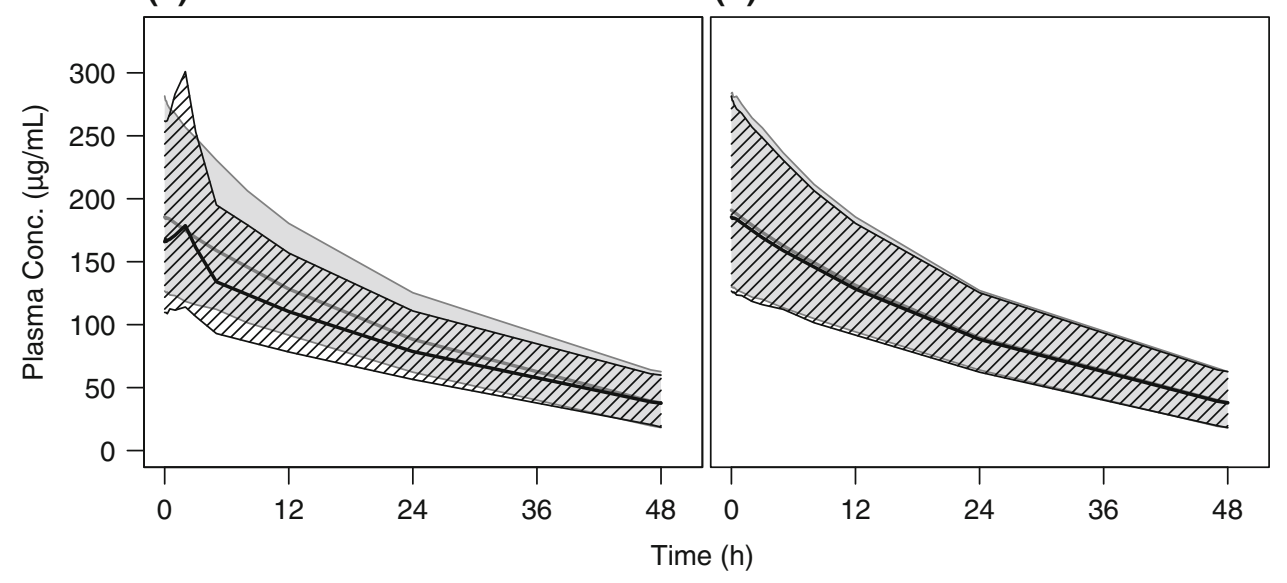

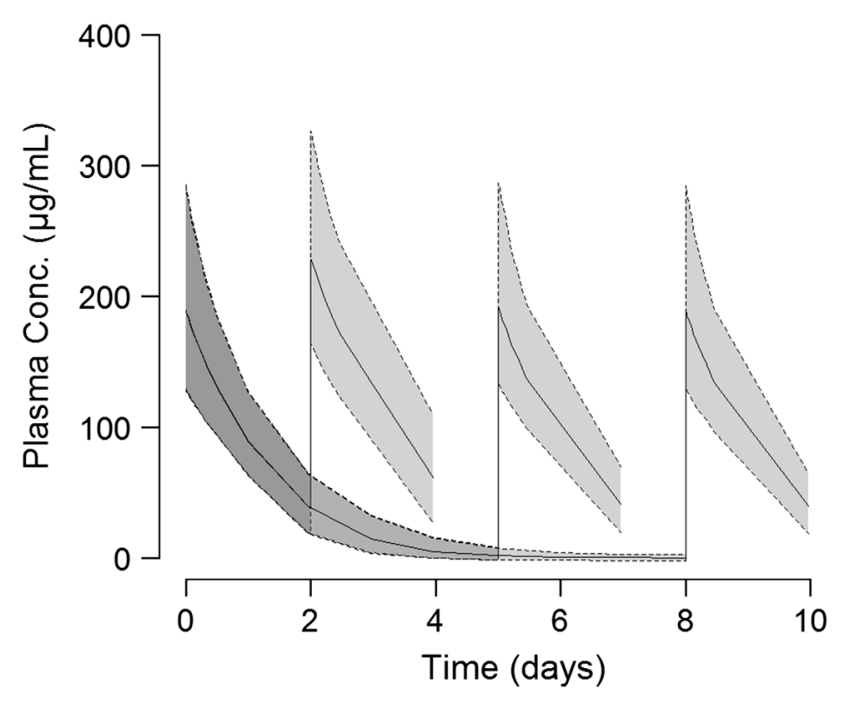

Fig. 4 Plasma concentration-time profiles after two simulated administrations of $510 \mathrm{mg}$ ferumoxytol in a combined population of healthy volunteers and CKD patients not on haemodialysis. The second dose was administered 2, 5 or 8 days after the first dose as an illustration of approved ferumoxytol dosing regimens. Solid lines and shaded areas represent median and $90 \%$ prediction interval, respectively. $C K D$ chronic kidney disease

includes dose adjustment for patients with a body weight of less than $50 \mathrm{~kg}$. The identified effects of body weight and sex on central volume are not considered to warrant any further dose adjustment.

Some identified covariates were specific to the haemodialysis process. Prior to this analysis, it had been assumed that central volume would change during the course of haemodialysis due to the fluid loss, and this hypothesis was tested during model development. A typical volume reduction of $0.59 \mathrm{~L}$ over the haemodialysis period of $3 \mathrm{~h}$ was estimated. This is in line with reported blood volume reduction of $\sim 10 \%$ during haemodialysis [20]. In addition, the extent of weight loss during haemodialysis was identified as an indicator of the initial central volume as subjects with larger differences between pre- and postdialysis weight initially had a higher volume of distribution. From a physiological point of view, this relationship appears reasonable as a higher weight loss would be expected in subjects with a high fluid retention and thus higher volume at the start of dialysis. In principle, a relationship between WLO and VSLOPE might also be reasonable as most dialysis machines are generally volumetric [25], meaning they allow dialysate pressure to change to achieve the prescribed target weight. Indeed, when using such equipments, weight loss can occur in a linear manner per unit of time with high precision. However, as BSV on VSLOPE was not included during model development, its relationship with WLO was not tested. Remaining plasma PK variability, which is currently described using BSV terms, indicates that other covariates not included in the present analysis could assist in further reducing unexplained variability.

It is acknowledged that the developed model is empirical in nature. This means that ferumoxytol plasma clearance is considered to mostly represent iron sequestration into the reticuloendothelial system and not a systemic clearance [26]. Covariate analysis showed that baseline iron panel parameters did not influence plasma ferumoxytol PK. Differences in the plasma concentration-time profiles across populations could be explained by the effects of haemodialysis on the central volume of distribution alone, indicating comparable ferumoxytol plasma PK between populations, even if iron panel baseline values differ. It should nonetheless be noted that the sample size of the CKD population included in the model was limited. Therefore, the results presented in this manuscript should be regarded as supportive evidence for the similarities in ferumoxytol plasma PK between populations, not as proof thereof. It should also be noted that the iron disposition itself has not been investigated as part of this popPK analysis. While the final model was considered appropriate 
Table 6 NCA results for simulated profiles in a combined group of healthy volunteers and CKD patients without haemodialysis after single and repeat ferumoxytol administration

\begin{tabular}{|c|c|c|c|c|c|}
\hline Dosing schedule & Percentile & $C_{\max }(\mu \mathrm{g} / \mathrm{mL})$ & $\mathrm{AUC}_{\mathrm{inf}}{ }^{\mathrm{a}}(\mu \mathrm{g} \cdot \mathrm{h} / \mathrm{mL})$ & $\operatorname{AUC}_{0-48 \mathrm{~h}}(\mu \mathrm{g} \cdot \mathrm{h} / \mathrm{mL})$ & $t_{1 / 2}(\mathrm{~h})$ \\
\hline \multirow[t]{3}{*}{$510 \mathrm{mg}$ : single dose } & Median & 208 & 5,960 & 4,750 & 19.9 \\
\hline & 5 th & 144 & 4,250 & 3,530 & 12.1 \\
\hline & 95 th & 305 & 8,640 & 6,510 & 33.2 \\
\hline \multirow[t]{3}{*}{$2 \times 510 \mathrm{mg}: 2$ days apart ${ }^{\mathrm{b}}$} & Median & 250 & 13,500 & 4,750 & 24.7 \\
\hline & 5 th & 182 & 9,390 & 3,530 & 14.2 \\
\hline & 95 th & 349 & 20,700 & 6,510 & 43.6 \\
\hline \multirow[t]{3}{*}{$2 \times 510 \mathrm{mg}: 5$ days apart $^{\mathrm{b}}$} & Median & 209 & 12,200 & 4,760 & 21.0 \\
\hline & 5 th & 148 & 8,710 & 3,530 & 13.0 \\
\hline & 95 th & 307 & 17,300 & 6,580 & 34.8 \\
\hline \multirow[t]{3}{*}{$2 \times 510 \mathrm{mg}: 8$ days apart $^{\mathrm{b}}$} & Median & 205 & 12,000 & 4,740 & 20.9 \\
\hline & 5 th & 144 & 8,660 & 3,530 & 12.9 \\
\hline & 95th & 303 & 16,900 & 6,500 & 33.4 \\
\hline
\end{tabular}

NCA non-compartmental analysis, $C K D$ chronic kidney disease, $C_{\max }$ maximum concentration, $A U C_{i n f}$ area under the curve from time zero to infinity, $A U C_{0-48}$ area under the curve from time zero to $48 \mathrm{~h}, t_{1 / 2}$ elimination half-life

a $\mathrm{AUC}_{\mathrm{inf}}$ for $2 \times 510 \mathrm{mg}$ represents the exposure of two doses

${ }^{\mathrm{b}} C_{\max }$ and $t_{1 / 2}$ for $2 \times 510 \mathrm{mg}$ determined from the second dose

for the intended purpose of describing and comparing ferumoxytol plasma PK across populations, more physiological approaches may be warranted to better describe the fate of the iron once it has been released from the ferumoxytol complex, including potential differences between HVs and CKD populations.

Simulation of repeated dosing with varying dosing intervals demonstrated that ferumoxytol accumulation is small. Simulations were also performed to illustrate exposure differences that arise as a result of haemodialysis and to compare these with exposures in HVs and nonhaemodialysis CKD patients. While maximum concentrations and AUC values were marginally lower for the haemodialysis patients, no difference in exposure was predicted between $\mathrm{HVs}$ and non-haemodialysis CKD patients.

Overall, CKD is an example of a chronic disease, with a predictable prognosis and course, where IDA can be caused by decreased iron availability, blood loss and increased iron utilization in response to erythropoietin-stimulatingagent utilization [2, 3]. It was therefore an appropriate population to explore PK via modelling approaches and to extrapolate this to an all-cause IDA population, where ID is caused by a variety of mechanisms. Given that the differences in plasma PK profiles between CKD patients and HVs are not related to intrinsic factors and were overall very marginal, it is expected that the PK of these two groups is representative of that of other populations, including patient subgroups of all-cause IDA, provided there are no other extrinsic factors causing clinically significant perturbations on the PK parameters, in particular
$V 1$ (e.g. extreme blood loss). This bridging strategy was used to support the Marketing Authorization Application for ferumoxytol in the all-cause IDA indication, and the methodology was deemed as acceptable to this Regulatory Agency for registration and labelling purposes.

\section{Conclusions}

Body weight and sex were found to influence the central volume of distribution but did not warrant any further dose adjustment. Differences in plasma PK profiles between HVs and CKD patients with haemodialysis could be fully explained by the volume loss during haemodialysis, and it was shown that the overall effect of haemodialysis on ferumoxytol PK is small.

The results from the present popPK meta-analysis support the hypothesis that underlying pathology investigated in this analysis is not relevant for explaining variability in plasma PK, and that CKD patients are similar to HVs. It is thus expected that the PK of these two groups is representative of other populations, including patient subgroups with all-cause IDA. The analysis thus increased the understanding of the likely ferumoxytol plasma exposures in the general IDA population and provided valuable support for the bridging strategy in the respective Marketing Authorization Application for ferumoxytol.

Acknowledgments The authors would like to acknowledge Luann Phillips and Serge Guzy for active discussions on the model code. The analysed studies were funded by AMAG Pharmaceuticals, Inc. Nele Plock, Axel Facius, Gezim Lahu, Nolan Wood and Aaron Deveney 
are employees of Takeda. Timothy Frigo is an employee of AMAG Pharmaceuticals.

Open Access This article is distributed under the terms of the Creative Commons Attribution Noncommercial License which permits any noncommercial use, distribution, and reproduction in any medium, provided the original author(s) and the source are credited.

\section{References}

1. Jha V, Garcia-Garcia G, Iseki K, Li Z, Naicker S, Plattner B, et al. Chronic kidney disease: global dimension and perspectives [published erratum appears in Lancet 2013;382(9888):208]. Lancet. 2013;382(9888):260-72.

2. Akmal M, Sawelson S, Karubian F, Gadallah M. The prevalence and significance of occult blood loss in patients with predialysis advanced chronic renal failure (CRF), or receiving dialytic therapy. Clin Nephrol. 1994;42(3):198-202.

3. Kooistra MP, van Es A, Struyvenberg A, Marx JJ. Iron metabolism in patients with the anaemia of end-stage renal disease during treatment with recombinant human erythropoietin. Br J Haematol. 1991;79(4):634-9.

4. Locatelli F, Aljama P, Bárány P, Canaud B, Carrera F, Eckardt KU, Hörl WH, Macdougal IC, Macleod A, Wiecek A, Cameron S, European Best Practice Guidelines Working Group. Revised European best practice guidelines for the management of anaemia in patients with chronic renal failure. Nephrol Dial Transplant. 2004;19(Suppl 2):21-47.

5. Clark SF. Iron deficiency anemia. Nutr Clin Pract. 2008;23(2): $128-41$.

6. Santiago P. Ferrous versus ferric oral iron formulations for the treatment of iron deficiency: a clinical overview. Sci World J. 2012;2012:846824. doi:10.1100/2012/846824 (Epub 2012 May 2).

7. Litton E, Xiao J, Ho KM. Safety and efficacy of intravenous iron therapy in reducing requirement for allogeneic blood transfusion: systematic review and meta-analysis of randomised clinical trials. BMJ. 2013;347:f4822.

8. McCormack PL. Ferumoxytol: in iron deficiency anaemia in adults with chronic kidney disease. Drugs. 2012;72(15):2013-22.

9. Provenzano R, Schiller B, Rao M, Coyne D, Brenner L, Pereira BJ. Ferumoxytol as an intravenous iron replacement therapy in hemodialysis patients. Clin J Am Soc Nephrol. 2009;4(2):386-93.

10. Spinowitz BS, Schwenk MH, Jacobs PM, Bolton WK, Kaplan MR, Charytan C, Galler M. The safety and efficacy of ferumoxytol therapy in anemic chronic kidney disease patients. Kidney Int. 2005;68(4):1801-7.
11. Singh A, Patel T, Hertel J, Bernardo M, Kausz A, Brenner L. Safety of ferumoxytol in patients with anemia and CKD. Am J Kidney Dis. 2008;52(5):907-15.

12. Pai AB, Nielsen JC, Kausz A, Miller P, Owen JS. Plasma pharmacokinetics of two consecutive doses of ferumoxytol in healthy subjects. Clin Pharmacol Ther. 2010;88(2):237-42.

13. Leypoldt JK, Cheung AK, Delmez JA, Gassman JJ, Levin NW, Lewis JA, Lewis JL, Rocco MV. Relationship between volume status and blood pressure during chronic hemodialysis. Kidney Int. 2002;61(1):266-75.

14. Mitra S, Chamney P, Greenwood R, Farrington K. Serial determinations of absolute plasma volume with indocyanine green during hemodialysis. J Am Soc Nephrol. 2003;14(9):2345-51.

15. The International Conference on Harmonisation of technical requirements for registration of pharmaceuticals for human use (ICH). Available from: http://www.ich.org.

16. Landry R, Jacobs PM, Davis R, Shenouda M, Bolton WK. Pharmacokinetic study of ferumoxytol: a new iron replacement therapy in normal subjects and hemodialysis patients. Am J Nephrol. 2005;25(4):400-10.

17. Beal SL, Boeckmann AJ, Sheiner LB. NONMEM users guide. Parts I-VIII. ICON Development Solutions.

18. Holford N. The visual predictive check-superiority to standard diagnostic (Rorschach) Plots. 2005. Available from: http://www. page-meeting.org/?abstract=738. Accessed 7 Apr 2014.

19. Feraheme: dosage and administration. Full prescribing information. Available from: http://www.feraheme.com/. Accessed 7 Apr 2014.

20. Katzarski KS. Monitoring of blood volume during haemodialysis treatment of acute renal and multiple organ failures. Nephrol Dial Transplant. 1996;11(Suppl 8):20-3.

21. Savic RM, Karlsson MO. Importance of shrinkage in empirical bayes estimates for diagnostics: problems and solutions. AAPS J. 2009;11(3):558-69.

22. Holford N, Kirkpatrick C, Duffull S. NONMEM termination status is not an important indicator of the quality of bootstrap parameter estimates. 2006. Available from: http://www.pagemeeting.org/?abstract=992. Accessed 14 Apr 2014.

23. Benet LZ, Zia-Amirhosseini P. Basic principles of pharmacokinetics. Toxicol Pathol. 1995;23(2):115-23.

24. Rienso. Summary of product characteristics. Available from: http://www.ema.europa.eu/docs/en_GB/document_library/EPAR_-Product_Information/human/002215/WC500129749.pdf. Accessed 14 Apr 2014.

25. Irwin RS, Rippe JM. Irwin and Rippe's intensive care medicine. 5th ed. USA: Lippincott Williams \& Wilkins; 2003. p. 991.

26. Spivak JL. Iron and the anemia of chronic disease. Oncology (Williston Park). 2002;16(9 Suppl 10):25-33. 